Bawden, F. C. \& Harrison, B. D. (1955). J. gen. Microbiol. 13, 494-508

\title{
Studies on the Multiplication of a Tobacco Necrosis Virus in Inoculated Leaves of French-bean Plants
}

\author{
By F. C. BAWDEN AND B. D. HARRISON* \\ Rothamsted Experimental Station, Harpenden, Hertfordshire
}

SUMMARY: By treating leaves of French bean (Phaseolus vulgaris L.) in various ways at intervals after they were inoculated with the Rothamsted tobacco necrosis virus, a series of events in infected cells was detected and approximately timed. Treating leaves with ribonuclease, or floating them in water, in the first hour after inoculation decreases the number of infections; these treatments fail to do so later, perhaps because the virus has become firmly attached to some host component, or because cells injured at inoculation have healed and no longer allow virus particles to diffuse out or ribonuclease in.

After $2 \mathrm{hr}$. at $25^{\circ}$ the virus is less readily inactivated by ultraviolet radiation than previously, suggesting that infected cells now contain more of substances that absorb radiation of $2537 \mathrm{~A}$. After $4 \mathrm{hr}$. the inactivation curve with ultraviolet radiation deviates from the course of a first-order reaction, probably because some infected cells now contain more than one potentially infective particle. After $6 \mathrm{hr}$. the formation of some lesions cannot be prevented by irradiation, suggesting that newly formed virus has spread from initially infected cells to deeper tissues, where it is protected from inactivation. At $16^{\circ}$ the mean time for virus to spread from the initially infected cells is $12.5 \mathrm{hr}$. and it probably spreads from some cells by $8 \mathrm{hr}$. and from most by $15 \mathrm{hr}$.

Newly formed virus is not detectable in extracts of inoculated leaves until after it has spread from the epidermis to deeper tissues. Up to $20 \mathrm{hr}$. after inoculation most of the extractable virus seems to come from the epidermis, but later it comes predominantly from other tissues.

When leaves of susceptible plants are rubbed with solutions of plant viruses, washed to remove surplus inoculum, and then macerated at intervals, there follows a 'latent' period during which the infectivity of successive samples of leaf sap not only fails to increase but usually decreases. With any given inoculum and host plant, provided the conditions are kept constant, the interval between inoculation and the time when new infective particles become detectable in the sap is reasonably constant, but the latent period differs with different viruses and hosts, and it also varies with changes in either the temperature or the virus content of the inoculum. With the Rothamsted tobacco necrosis virus in French bean, the virus-host combination with which we shall be mainly concerned, the minimum latent period at $22^{\circ}$ is about $10 \mathrm{hr}$. (Harrison, 1955). Little or nothing is known about what goes on during this period, and the experiments we describe below, in which leaves were subjected to a variety of treatments at different times after they were inoculated, were made to gain some indirect evidence about the sequence of events between the application of the inoculum and the occurrence of new infective virus.

* Present address: Scottish Horticultural Research Institute, Invergowrie, by Dundee. 


\section{METHODS}

The inoculum was sap expressed from leaves of French bean (Phaseolus vulgaris L. var. Prince) infected with the Rothamsted tobacco necrosis virus (RTNV) and showing well-developed necrotic lesions. The sap was kept frozen, and samples were thawed and clarified by centrifuging at 6000 r.p.m. when needed. Inocula were diluted in distilled water. For experiments, and for assays by the local-lesion method, the primary leaves of French bean were used, and the apical shoots were removed before the plants were inoculated. Unless otherwise stated, plants were raised and kept during the period of an experiment in the fluctuating conditions of a glasshouse, with an average temperature of $20^{\circ}$ and with no supplementary light. When experiments were made at a constant temperature, the plants were kept in a glass-sided incubator heated by four thermostatically controlled, electric strip-heaters. The air was kept moving by a fan hanging from the roof of the incubator, and the temperature did not vary by more than $1^{\circ}$ from the mean.

Leaves were inoculated by rubbing their upper surfaces as evenly as possible with the forefinger wetted with inoculum. When 'Celite', a diatomaceous earth sold by Johns-Manville, was used to increase the number of lesions produced by an inoculum (Kalmus \& Kassanis, 1945), it was suspended in the inoculum. Infectivity assays were made by the local-lesion, half-leaf method. When several inocula or treatments were to be compared, they were distributed so that each occurred on at least six half-leaves, and equally often on left- and right-hand halves.

Two sources of ultraviolet radiation (UV) were used, both low-pressure mercury discharge lamps. One, lamp $B$, made by the Thermal Syndicate Ltd., was fitted with a chromium-plated, cylindrical reflector; the intensity of radiation, most of which was wavelength $2537 \mathrm{~A}$, at $20 \mathrm{~cm}$. was $870 \mu \mathrm{W} / \mathrm{sq}$.cm. The other, lamp $W$, a tube $60 \mathrm{~cm}$. long made by Hanovia Ltd., who state that over $95 \%$ of the radiation is of wavelength $2537 \mathrm{~A}$, was fitted with an ozonereducing filter; at $20 \mathrm{~cm}$. from the tube it produced similar effects to lamp $B$ in about half the time. All leaves were exposed at $20 \mathrm{~cm}$. from the tubes.

Crystalline ribonuclease was prepared from beef pancreas by Kunitz's (1940) method.

\section{RESULTS}

The effects of exposing inoculated leaves to ultraviolet radiation

As ultraviolet radiation can destroy the infectivity of plant viruses and also the ability of plant cells to support the multiplication of viruses (Bawden $\&$ Kleczkowski, 1952, 1953; Benda, 1955), irradiation of recently inoculated leaves might prevent lesions from forming either because the infecting virus was inactivated or because the host cells were affected. For various reasons, we think that most of the lesions which failed to develop in our experiments did so because the virus was inactivated and that probably few cells were so affected by the radiation that they could not support virus multiplication and yet still contain infective virus. 
First, exposures to the same amount of radiation decrease the numbers of lesions much more when they are given shortly after than when given immediately before inoculation. For example, giving exposures of 0.5, 1, 2 and 3 min. with lamp $B$, the lesions formed on irradiated half-leaves, expressed as a percentage of those on the unirradiated halves, were 50, 29, 3 and 1 when the leaves were exposed after inoculation, and 80, 80, 63 and 17 when they were exposed before inoculation. Secondly, when the logarithms of such percentages

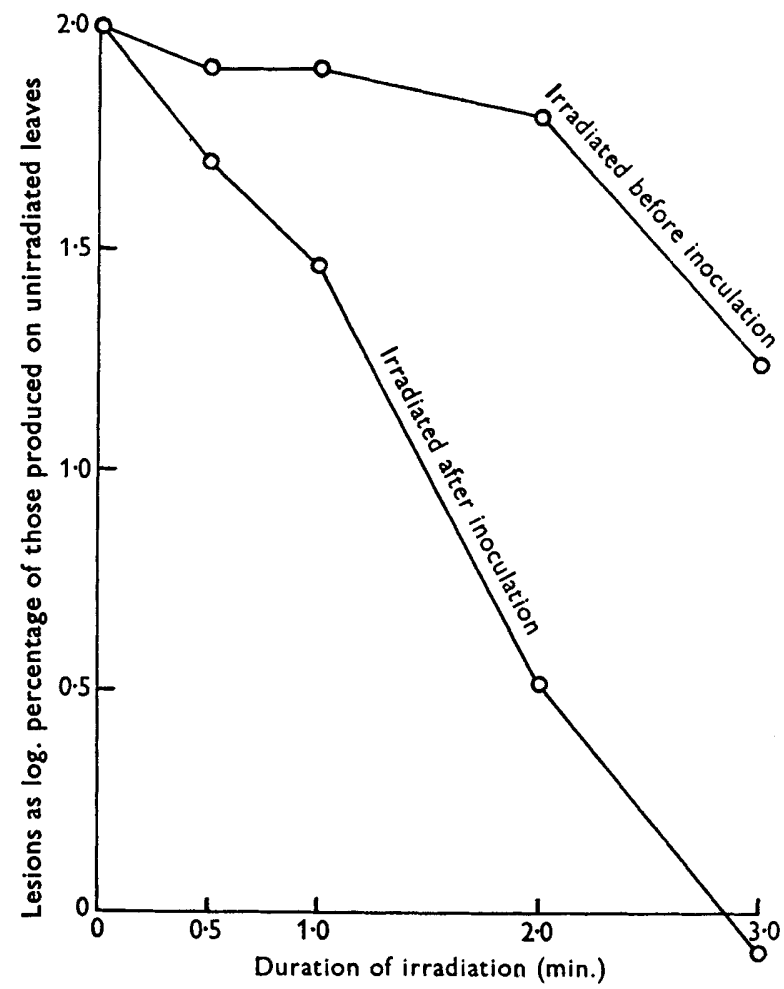

Fig. 1. Effect on numbers of lesions of irradiating French-bean leaves, for various times with lamp $B$, before and after they were inoculated with the Rothamsted tobacco necrosis virus.

are plotted against the time of exposure to UV, the lines for exposures after inoculation are straight, as they are for the inactivation of virus preparations by UV in vitro, typical of the course of a first-order reaction and often called a 'single-hit' process. By contrast, the lines for exposures before inoculation are curved and deviate considerably from the course of a first-order reaction (Fig. 1).

Thirdly, if effects on the host plant were comparable to those on the infecting virus, irradiation of leaves after inoculation should decrease lesion numbers similarly, regardless of the sensitivity to UV of the virus used; but this is not so. When we inoculated leaves of Nicotiana glutinosa with two 
strains of tobacco mosaic virus that differ considerably in the ease with which they are inactivated in vitro by exposure to UV (Siegel \& Wildman, 1954; Bawden \& Kleczkowski, 1955), and then exposed the leaves to equal amounts of irradiation, proportionally many fewer infections were obtained with the more sensitive strain U2 than with the type strain.

Effects on the host plant may have contributed something to the total decrease in numbers of lesions when inoculated leaves were given the longer exposures to UV, but this contribution was probably too small to prevent the decrease from being used to estimate the inactivation of the infecting virus. To mitigate damage to the leaves and to stop them from becoming bronzed, whenever possible they were kept in daylight for some hours immediately after they were irradiated. With our exposures, damage to the host probably did not extend deeper than the epidermis. Benda (1955) found that one-third of the incident radiation of $2537 \mathrm{~A}$ could be transmitted by pieces stripped from the upper epidermis of French bean leaves, but less than this will enter the palisade cells and much of what does is probably absorbed by the first layer of chloroplasts. With the largest exposures to UV that we used, although the epidermis dies when the leaves are kept in the dark, the palisade cells not only survive but seem unharmed (Bawden \& Kleczkowski, 1952). Also, when the upper surface of leaves is inoculated with RTNV and the lower surface is then exposed to much more radiation than is needed to kill its epidermis, numbers of infections are unaffected.

On the assumption that inoculation introduces virus only into epidermal cells, and that only virus in these cells is affected by exposing leaves to UV, experiments were done to find how long the inoculated virus takes to multiply in the epidermis and to spread from there to deeper cells. Fig. 2 gives the combined results of two experiments at $16^{\circ}$, in which leaves were exposed to 3 min. radiation from lamp $B$ at different intervals after they were inoculated. The virus seems to have spread from some sites of infection within $8 \mathrm{hr}$. of inoculation and from $80 \%$ within $15 \mathrm{hr}$. The average time taken for newly formed virus to enter the mesophyll from the initially infected epidermis can be taken as the interval between inoculation and when half the lesions that can be suppressed by irradiation immediately after inoculation form despite irradiation. Fig. 2 shows that the leaves irradiated immediately after inoculation produced $2 \%$ of the lesions produced by unirradiated leaves, so that the $50 \%$ suppression time was when irradiated leaves produced $51 \%$ of the number of lesions formed on the controls, which was $12.5 \mathrm{hr}$. after inoculation.

This $50 \%$ suppression time varies with the temperature; at $25^{\circ}$ it is $6 \mathrm{hr}$. for RTNV in French bean. It also differs with different viruses and host plants; with RTNV it is about twice as long in tobacco as in French bean; at $25^{\circ}$ it is $5.5 \mathrm{hr}$. for tomato aucuba mosaic virus in tobacco and in Nicotiana glutinosa, and it is about 13 and $19 \mathrm{hr}$., respectively, for tomato bushy stunt and tomato spotted wilt viruses in $N$. glutinosa. When leaves are exposed to the same amount of radiation immediately they have been inoculated, the proportion of lesions that develops is smaller with tomato spotted wilt virus than with RTNV or tomato bushy stunt virus, and smaller with these than 
with the tomato aucuba mosaic or the type strain of tobacco mosaic virus. The results with the last four agree with their relative sensitivities to UV when irradiated in vitro (Bawden \& Kleczkowski, 1953, 1955), from which it seems that tomato spotted wilt is the most sensitive of the viruses used.

To gain some information about changes in epidermal cells before newly formed virus moves out of them, experiments were made of the type described by Luria \& Latarjet (1947) with coliphages, and half-leaves were exposed to

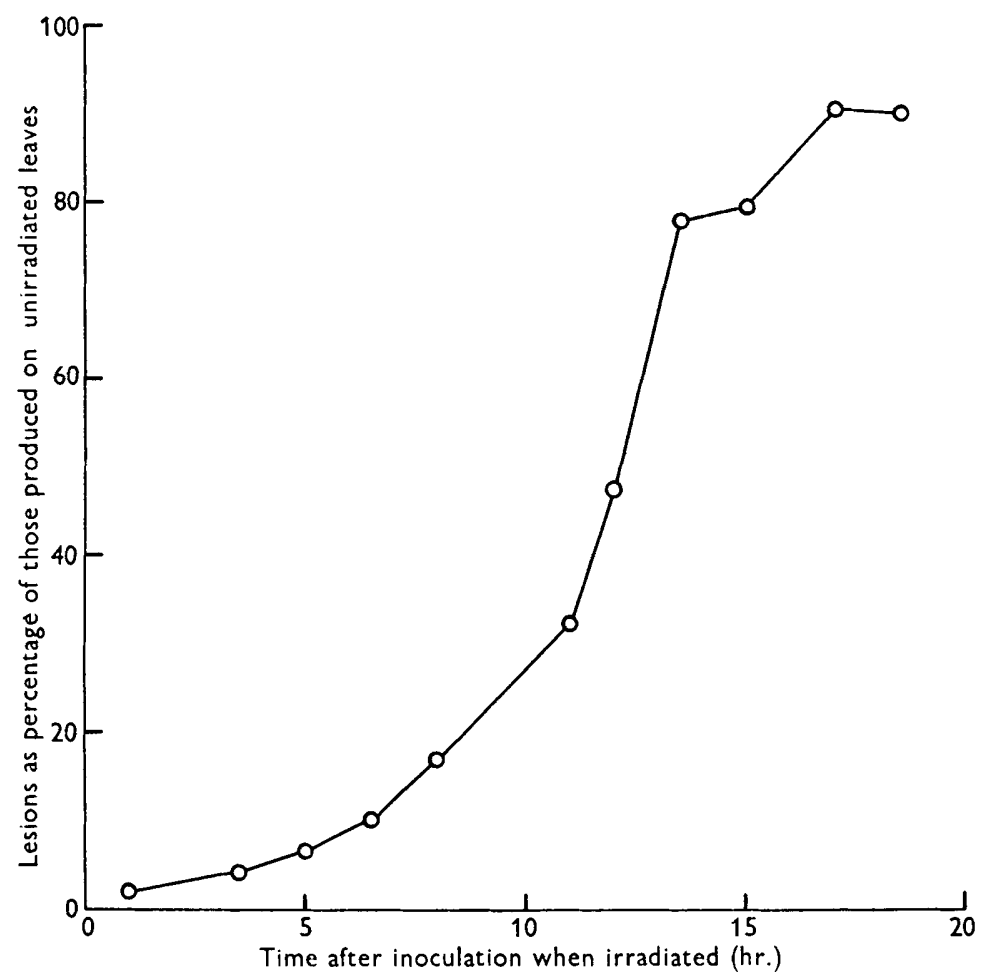

Fig. 2. Effect on numbers of lesions of irradiating French-bean leaves, for $3 \mathrm{~min}$. with $\operatorname{lamp} B$, at different intervals after they were inoculated with Rothamsted tobacco necrosis virus and kept at $16^{\circ}$.

four doses of UV $(20,40,80$ and 160 sec. with lamp $W)$ at different times after they were inoculated with RTNV. In each experiment, twelve batches of plants were inoculated and kept at $25^{\circ}$. The leaves were washed after inoculation. At three different times, four batches were removed from the incubator and one batch given each of the exposures to UV. The leaves were detached, and as some were still wet from washing, all were dipped in water, and half of each was irradiated: wetting did not influence the effects of irradiation. The times when leaves were inoculated were so arranged that the intervals between inoculation and irradiation were the same for leaves receiving each of the four doses of UV. After irradiation, the leaves were floated on water until the lesions developed. 
The average number of lesions as a percentage of the unirradiated controls was calculated for each treatment in each experiment, and the averages for all experiments are given in Table 1 . The average numbers of lesions per half-leaf on irradiated and control half-leaves were also calculated for each treatment, and were used to calculate the proportion of the virus that survived when the inoculated leaves were irradiated. Lesions counts, unlike plaque counts with phages, cannot be used directly for this purpose because the number of lesions produced by inocula is not linearly related to their virus content. To obtain values more representative of virus survival, the numbers of lesions given by any treatment and by its unirradiated control were interpolated on a curve obtained by plotting numbers of lesions obtained with inoculum applied at a

Table 1. The effect on lesion number of exposing French-bean leaves to various amounts of ultraviolet radiation at different times after inoculation

\begin{tabular}{|c|c|c|c|c|c|}
\hline \multirow{3}{*}{$\begin{array}{c}\text { Period after } \\
\text { inoculation } \\
(\mathrm{hr} .)\end{array}$} & \multicolumn{4}{|c|}{ Ultraviolet dose (sec.) } & \multirow{3}{*}{$\begin{array}{c}\text { No. of } \\
\text { experiments }\end{array}$} \\
\hline & 20 & 40 & 80 & 160 & \\
\hline & \multicolumn{4}{|c|}{ Number of lesions $(\%)^{*}$} & \\
\hline 0 & $53 \cdot 60$ & $21 \cdot 14$ & $4 \cdot 70$ & $1 \cdot 22$ & 5 \\
\hline 1 & $50 \cdot 83$ & $23 \cdot 20$ & $5 \cdot 02$ & $1 \cdot 65$ & 6 \\
\hline 2 & $69 \cdot 79$ & $49 \cdot 66$ & $29 \cdot 40$ & $6 \cdot 59$ & 9 \\
\hline 3 & $75 \cdot 37$ & 48.93 & $35 \cdot 10$ & $6 \cdot 52$ & 3 \\
\hline 4 & $76 \cdot 30$ & 66.93 & $48 \cdot 63$ & $13 \cdot 22$ & 8 \\
\hline 5 & $89 \cdot 3$ & $78 \cdot 7$ & $52 \cdot 7$ & $38 \cdot 3$ & 1 \\
\hline 6 & $87 \cdot 30$ & $82 \cdot 70$ & $62 \cdot 66$ & $50 \cdot 32$ & 5 \\
\hline 7 and 8 & $81 \cdot 22$ & $91 \cdot 88$ & $80 \cdot 12$ & $76 \cdot 44$ & 5 \\
\hline
\end{tabular}

* The numbers of lesions formed on irradiated leaves expressed as the percentage of the number that formed on the unirradiated controls.

Inoculum was infective sap at $1 / 100$, and plants were left at $25^{\circ}$.

range of dilutions, against the logarithm of the dilution. By finding what difference in virus content was needed to produce the same fall in lesion numbers as that produced by irradiation, the proportion of surviving active virus could be calculated. For example, if forty lesions were produced by the control and twenty by the irradiated leaves, the dilution curve showed that, to get this same result by dilution would require the inoculum to be diluted 1 in $\mathbf{2 . 4 6}$. In this example, then, where the irradiated leaves produced half as many lesions as the controls, the percentage of inoculated virus that survived irradiation was $100 / 2 \cdot 46=40 \cdot 6$. The average numbers of lesions per half-leaf produced with every treatment in each experiment were so transformed and are given in Table 2.

Fig. 3 shows the lines obtained when the logarithms of the percentages of virus that survived irradiation at different times after inoculation are plotted against the UV dose. Except for differences in the time scale, these lines resemble those given by coliphage $\mathrm{T} 7$ (Benzer, 1952). The lines for $5 \mathrm{~min}$. and $1 \mathrm{hr}$. after inoculation follow the same course and both are straight up to $80 \mathrm{sec}$. irradiation. No significance is attached to the deviation from straightness 
at 160 sec., for only $1 \%$ of the initial virus was then surviving and this may have survived because it was in cells that were for some reason shaded from the radiation. A straight line would be expected if irradiation prevented

Table 2. The proportion of infecting virus surviving in leaves given different ultraviolet doses at different times after inoculation

\begin{tabular}{|c|c|c|c|c|c|}
\hline \multirow{3}{*}{$\begin{array}{c}\text { Period after } \\
\text { inoculation } \\
(\mathrm{hr} .)\end{array}$} & \multicolumn{4}{|c|}{ Ultraviolet dose (sec.) } & \multirow{3}{*}{$\begin{array}{c}\text { No. of } \\
\text { experiments }\end{array}$} \\
\hline & 20 & 40 & 80 & 160 & \\
\hline & \multicolumn{4}{|c|}{ Number of lesions $(\%)^{*}$} & \\
\hline o & $43 \cdot 70$ & $16 \cdot 40$ & $3 \cdot 46$ & $0 \cdot 89$ & 5 \\
\hline 1 & $37 \cdot 70$ & $16 \cdot 26$ & $2 \cdot 89$ & $1 \cdot 02$ & 6 \\
\hline 2 & $62 \cdot 09$ & $40 \cdot 34$ & $22 \cdot 30$ & 4.22 & 9 \\
\hline 3 & $65 \cdot 23$ & $37 \cdot 00$ & $25 \cdot 47$ & $4 \cdot 67$ & 3 \\
\hline 4 & $67 \cdot 76$ & $58 \cdot 04$ & $38 \cdot 88$ & $8 \cdot 25$ & 8 \\
\hline 5 & $80 \cdot 5$ & $66 \cdot 8$ & $\mathbf{3 8} \cdot \mathbf{3}$ & $22 \cdot 4$ & 1 \\
\hline 6 & $83 \cdot 38$ & $74 \cdot 26$ & $51 \cdot 68$ & $39 \cdot 82$ & 5 \\
\hline 7 and 8 & $72 \cdot 24$ & $87 \cdot 00$ & $69 \cdot 22$ & $67 \cdot 38$ & 5 \\
\hline
\end{tabular}

* The numbers are calculated from the lesion totals given as averages in Table 1 , and transformed into the percentage of surviving virus by interpolation of a dilution curve.

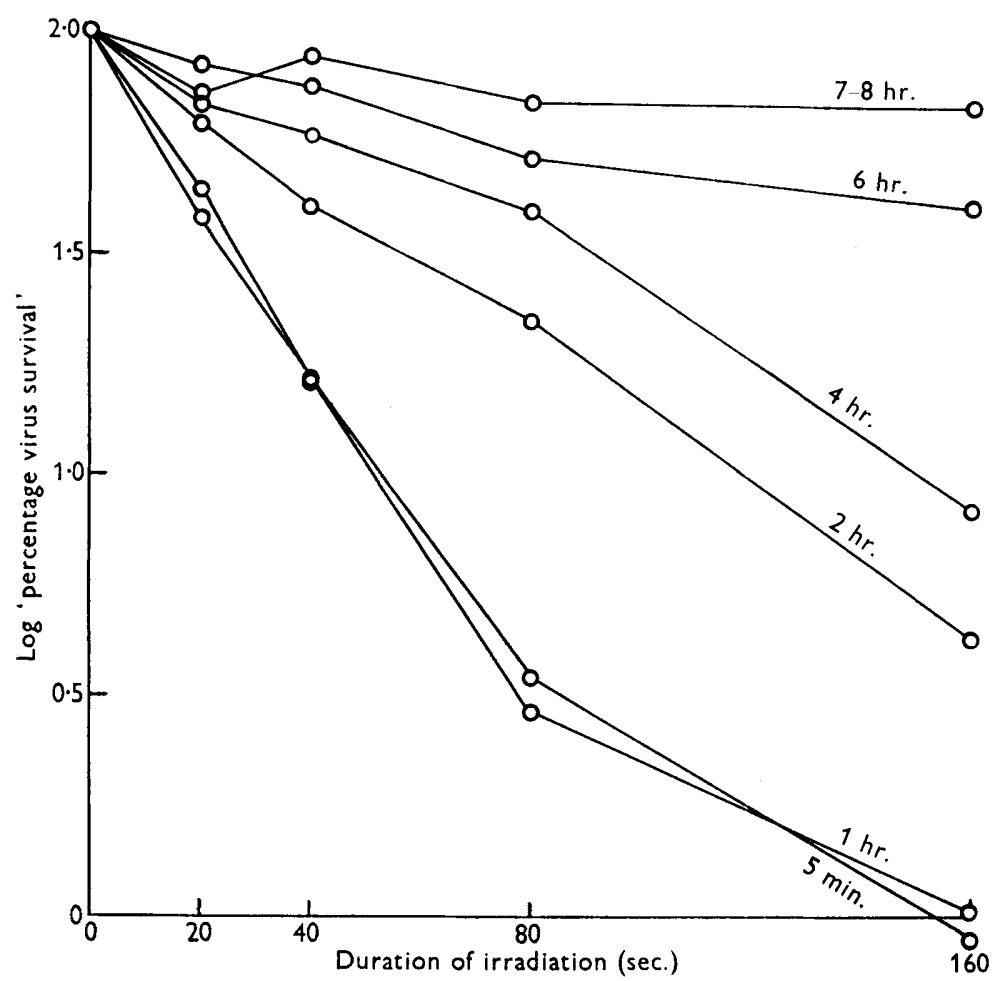

Fig. 3. Effect on the percentage of surviving virus of irradiating French-bean leaves, for various times with lamp $W$, at different intervals after they were inoculated with the Rothamsted tobacco necrosis virus and kept at $25^{\circ}$. 
lesion formation by inactivating one virus particle in each infected cell. The results suggest that, with inocula of the type used, most infections are caused by single particles. Any change that these single particles undergo during the first hour after inoculation seems not to affect their sensitivity to UV.

Except for a suggestion of flattening between 40 and 80 sec. irradiation, the line at $2 \mathrm{hr}$. after inoculation is still essentially straight, but the slope is less steep than at $1 \mathrm{hr}$. It seems that there is still only one virus particle/cell, but that it has become more difficult to inactivate by UV. This might have various explanations. The virus may have changed to a form more resistant to inactivation, or it may have combined with some host component that absorbs UV and protects it from the radiation. Alternatively, the infected cell may have synthesized substances that absorb UV; by analogy with infection by coliphages, which early leads to synthesis of nucleic acid, it is plausible to assume that the most likely substances are purines and pyrimidines. We think it unlikely that effects of UV on the ability of the host cells to sustain virus multiplication played any significant part in determining the course of this or any of the lines, but unfortunately there seems no way of distinguishing whether host sensitivity to UV is affected by the processes leading to virus synthesis. All that can be said is that UV exposures of 20 and 40 sec., which have no effect on the number of infections when given before inoculation, considerably decrease it when given up to $2 \mathrm{hr}$. after inoculation, and the line obtained at $2 \mathrm{hr}$. is not curved like that obtained for irradiation before inoculation (Fig. 1).

From 2 to $4 \mathrm{hr}$. after inoculation the resistance to inactivation by UV again increases and the $4 \mathrm{hr}$. line is not straight. The curvature shows only when leaves are irradiated for more than 20 sec., which suggests that, at some sites, inactivation of single infective particles still suffices to prevent a lesion from developing, but that, at others, more than one now have to be inactivated. Again, effects on the host cells may be influencing the curve, but that some cells probably contain more than one infective, or potentially infective, particle by $4 \mathrm{hr}$. after inoculation is indicated by the effects of the later irradiations. The $6 \mathrm{hr}$. line is also curved, but bends in the opposite way from the $4 \mathrm{hr}$. line; prolonging the exposure to UV from 80 to $160 \mathrm{sec}$. has little extra effect, showing that irradiation can no longer prevent lesions from forming at many infection sites. We take this fact as evidence that newly formed virus has spread to cells below the epidermis, and the results agree with the time estimated for this occurrence by the experiments using a single dose of UV. The failure of prolonged irradiation to prevent lesion formation shows even more obviously in the $7-8 \mathrm{hr}$. line, which suggests that, by this time at $25^{\circ}$, virus has entered the mesophyll from about $80 \%$ of the initial infection sites.

To gain information about the main sites of virus formation at later stages of infection, leaves were irradiated at intervals between 16 and $40 \mathrm{hr}$. after they were inoculated. These tests required infectivity assays on extracts from macerated leaves and they were not begun until $16 \mathrm{hr}$. after inoculation because until then the extracts contain too little virus to be assayed accurately. French-bean leaves were rubbed over their whole surfaces with infective sap diluted 1/100, washed thoroughly, and at various intervals the inoculated 
surfaces of eight half-leaves were irradiated for $3 \mathrm{~min}$. from lamp $B$. Immediately after irradiation, the terminal halves of the leaves were cut off, and the irradiated and unirradiated quarters were separated by cutting out the mid-rib. The eight irradiated quarter-leaves were pooled, macerated and the sap expressed and frozen: the unirradiated quarter-leaves were treated in the same way. At the end of an experiment, the samples of sap were thawed, clarified by centrifuging, and their infectivities compared. The basal halves of the leaves were left on the plants to observe how irradiation affected lesion formation. Irradiation at $16 \mathrm{hr}$. usually slightly decreased the number of lesions, but not after $19 \mathrm{hr}$. Lesions that developed on irradiated parts were often smaller than others; they began to appear about $40 \mathrm{hr}$. after inoculation and if irradiated then the usual black lesion was surrounded by a brown halo.

The results of four experiments are given in Table 3, where the numbers of lesions produced by samples of sap from the irradiated quarters of leaves are expressed as the percentages of the numbers produced by the unirradiated controls. Although these numbers will not exactly reflect the relative virus contents of the two lots of sap, they will serve as approximations. The differences between different experiments probably reflect the fact that the temperatures were not controlled, but the general trend is clear. At $16 \mathrm{hr}$. most of the newly formed virus is in the epidermis, but by $19 \mathrm{hr}$. a half is coming from the mesophyll. Between 19 and $24 \mathrm{hr}$. the proportion of the total extractable virus that is inactivated by exposing leaves to UV changed only slightly, suggesting that during this period virus was multiplying equally in epidermal and other cells. By $\mathbf{4 0} \mathrm{hr}$., however, irradiating inactivates only a small proportion of the total extractable virus; this probably means that the main suppliers of virus are now deeper cells, but is not wholly conclusive because lesions are now forming and the black necrotic cells may absorb UV and protect virus particles from inactivation.

The increase in virus content of the control leaves can be estimated in arbitrary units by finding at what dilution the samples of sap obtained at different times give similar numbers of lesions, and then multiplying the numbers of lesions by the dilution. For Expt. D in Table 3, for example, the relative virus contents at $16.5,19.5,21.5$ and $24 \mathrm{hr}$. after inoculation were, respectively, 155, 427, 3055 and 15425 units, of which 119, 189, 1326 and 5553 could be inactivated by irradiating leaves. This suggests that, during this period, virus continued to be produced in the epidermis, but that an increasingly large proportion of the total came from deeper cells as the infection proceeded. Combining the results from various tests, it can be concluded that for the first $8 \mathrm{hr}$. after inoculation new virus is produced only by the epidermal cells infected at inoculation; subsequently, it may continue to come from these, but is also now beginning to come from nearby cells, probably both epidermal and mesophyll. There is no evidence to suggest that any one type of leaf cell produces more virus than any other, and that most ultimately comes from cells other than the epidermis is to be expected because there are more of these other cells in the leaf. In seeming to occur more or less equally in all leaf cells, RTNV resembles tobacco mosaic virus in systemically infected tobacco 
leaves and differs from two aphid-transmitted viruses, cabbage black ringspot and henbane mosaic, with which most of the extractable virus seems to be contained in the epidermis (Bawden, Hamlyn \& Watson, 1954).

Table 3. The proportion of tobacco necrosis virus unaffected by ultraviolet radiation in leaves at different times after inoculation

\begin{tabular}{|c|c|c|c|c|c|c|}
\hline & \multicolumn{5}{|c|}{$\begin{array}{c}\text { Time of irradiation (hours after } \\
\text { inoculation) }\end{array}$} & \multirow{3}{*}{$\begin{array}{c}\text { Average } \\
\text { temperature }\left(^{\circ}\right)\end{array}$} \\
\hline & $16 \cdot 5$ & $19 \cdot 5$ & $\mathbf{2 1 . 5}$ & $\mathbf{2 4} \cdot 0$ & $40 \cdot 5$ & \\
\hline Exnt & \multicolumn{5}{|c|}{ Number of lesions $(\%)^{*}$} & \\
\hline $\mathbf{A}$ & $4 \cdot 0$ & $32 \cdot 0$ & $52 \cdot 8$ & $60 \cdot 4$ & $77 \cdot 1$ & $19 \cdot 5$ \\
\hline $\mathbf{B}$ & $28 \cdot 9$ & $52 \cdot 4$ & $19 \cdot 1$ & $60 \cdot 1$ & $98 \cdot 4$ & $19 \cdot 0$ \\
\hline $\mathbf{C}$ & $18 \cdot 0$ & $53 \cdot 5$ & $54 \cdot 5$ & $53 \cdot 7$ & $76 \cdot 5$ & $21 \cdot 5$ \\
\hline D & $23 \cdot 5$ & $55 \cdot 7$ & $56 \cdot 6$ & $64 \cdot 0$ & $97 \cdot 4$ & $22 \cdot 0$ \\
\hline Average $(X)$ & $18 \cdot 6$ & $48 \cdot 4$ & $45 \cdot 8$ & $59 \cdot 6$ & $87 \cdot 4$ & - \\
\hline $100-\dot{X}$ & $81 \cdot 4$ & $51 \cdot 6$ & $54 \cdot 2$ & $40 \cdot 4$ & $12 \cdot 6$ & - \\
\hline
\end{tabular}

* The numbers of lesions produced by sap from irradiated leaves expressed as percentages of those produced by sap from control unirradiated leaves.

The inoculum was infective sap at $1 / 100$, which produced about 75 lesions per half-leaf.

\section{Treatment of inoculated leaves with pancreatic ribonuclease}

Many substances which do not destroy plant viruses in vitro when incorporated in inocula prevent the viruses from infecting their host plants. Ribonuclease is one of the most powerful of these inhibitors of infection and, at $5 \mathrm{mg}$./l., it prevents potent preparations of RTNV from causing any lesions in French-bean leaves. To gain some information about the phase of infection that the enzyme affects, we have treated inoculated leaves with it at various intervals after inoculation. The leaves were treated in two ways, either rubbed with $50 \mathrm{mg}$./1. solutions of ribonuclease, or immersed for $15 \mathrm{sec}$. in the enzyme solution. As controls, comparable leaves were treated similarly with water. Neither of the methods of applying ribonuclease after inoculation decreased numbers of infections nearly as much as does incorporating the enzyme in the inoculum, possibly because they did not introduce the enzyme into all infected cells, which almost necessarily occurs when mixtures are inoculated, because the enzyme and virus combine in vitro. On average, rubbing with solutions of the enzyme at 5, 15, 30 and $60 \mathrm{~min}$. after inoculation decreased the numbers of lesions to 19, 40, 42 and $90 \%$ of those produced on the control leaves, and immersing in the solutions decreased them to $10,21,37$ and $80 \%$. The greater effect of immersing may be apparent rather than real, because rubbing with water alone decreased the numbers of lesions more than did immersion in water.

Clearly, ribonuclease can prevent infections if it is applied to leaves soon after they are inoculated and its ability to do so decreases rapidly with increasing time after inoculation, but it is less clear how to interpret this behaviour. One obvious interpretation is that the enzyme affects only a very 
early stage in the processes that lead to virus multiplication, a stage that has ended before any change is detectable in the resistance of the infecting particles to UV. The time during which the enzyme has any large effect is approximately the same as that needed for particles of potato virus $\mathbf{X}$ that have been inactivated by UV to reach the state in inoculated leaves where their ability to multiply can be restored by visible light (Bawden \& Kleczkowski, 1955). By analogy with the behaviour of infecting coli phages, this early stage might be, as suggested by Casterman \& Jeener (1955) for tobacco mosaic virus, the nucleic acid separating from the protein part of the virus and so becoming susceptible to hydrolysis by ribonuclease; or it might be the attachment of the virus particles to some specific component of the host cells, and that this attachment is prevented by ribonuclease, as it seems to prevent the attachment of a Rhizobium phage to its host (Kleczkowski \& Kleczkowski, 1954).

There is, though, another equally plausible interpretation for the fact that ribonuclease acts for only a short time after inoculation, namely, that for only a short time after inoculation are cells permeable to it. Ribonuclease is a large molecule and, like virus particles, will probably not readily penetrate uninjured leaves. Also, the length of time after inoculation during which ribonuclease decreases lesion numbers is about the same as that during which rubbed leaves remain susceptible to infection by suspensions of virus sprayed over them. For example, in experiments in which French-bean leaves were rubbed with suspensions of 'Celite' in distilled water and then sprayed at intervals with infective sap at $1 / 20$, the numbers of lesions formed on 12 half-leaves sprayed at $0 \cdot 1,0 \cdot 25,0 \cdot 5,1,2,4$ and $24 \mathrm{hr}$. after rubbing were $3355,2702,2165$, $873,87,32$ and 7 . Thus the susceptibility of the rubbed leaves to infection fell greatly during the first hour, and if this reflects the repair of wounds to the cells and the restoring of a barrier to the entry of virus particles, the same repair may also prevent the entry of ribonuclease.

\section{Effect of floating and rubbing inoculated leaves}

To assess the extent to which ribonuclease decreased infections when applied to inoculated leaves, comparisons had to be made with leaves treated comparably with water, for floating in water or rubbing with the forefinger wet with water also decreases the numbers of lesions produced by RTNV in French-bean leaves. The effect of floating is less than with Nicotiana glutinosa leaves inoculated with tobacco mosaic virus and it also operates for a shorter time after inoculation (Bawden \& Kassanis, 1954). The total lesions from three experiments in which leaves were floated in water with their inoculated surfaces upwards at intervals of $0 \cdot 1,0.5,1,2,4$ and $8 \mathrm{hr}$. after inoculation were 1477, 1913, 2490, 2803, 2886 and 2952. Washing freshly inoculated leaves in water also decreases the numbers of lesions that form, but this effect is not additive to the one obtained by floating continuously in water. Both probably act by removing particles from cells in which they otherwise would have remained and multiplied, and little RTNV seems to be removable after the first $30 \mathrm{~min}$. Whether the virus particles have by then become firmly attached to some 
component of the host cell, or whether the permeability of the cells has decreased by the healing of wounds, cannot be concluded.

Rubbing leaves with the forefinger wet with water decreases numbers of lesions when done at longer intervals after inoculating the virus. When rubbed at $0 \cdot 1,1,2,4,6$ and $8 \mathrm{hr}$. after inoculation, leaves produced 39, 63, 75, 83, 86 and $97 \%$ of the number of lesions produced on unrubbed leaves. Quarter of the total effect of rubbing is still obtained at 4-6 hr. after inoculation; the results of the experiments exposing inoculated leaves to UV suggest that this is the period when new virus particles are beginning to form and to invade deeper cells. Until this has happened, rubbing seems still able to prevent a lesion from developing. It presumably does so by injuring (perhaps killing) infected epidermal cells so that virus particles can no longer be synthesized in or move from them.

Table 4. The number of lesions in French-bean leaves inoculated once (V) or twice (VV) with a tobacco necrosis virus, and rubbed with water before $(W V)$ or after $(V W)$ inoculation

\begin{tabular}{|c|c|c|c|c|}
\hline Expt. & $\mathbf{v}$ & vw & Wv & Vv \\
\hline $\mathbf{A}$ & 553 & 492 & 488 & 754 \\
\hline B & 141 & 108 & 90 & 173 \\
\hline C & 2050 & 418 & 312 & 989 \\
\hline D & 356 & 119 & 63 & 196 \\
\hline $\mathbf{E}$ & 510 & 335 & 359 & 835 \\
\hline $\mathbf{F}$ & 98 & 71 & 59 & 127 \\
\hline G & 429 & 459 & 494 & 743 \\
\hline \multirow[t]{2}{*}{ H } & 147 & 106 & 118 & 217 \\
\hline & 4284 & 2108 & 1983 & 4034 \\
\hline
\end{tabular}

The numbers are the total lesions produced on 10 leaves. The leaves were not washed after inoculation and the interval between any two successive treatments was 15 min. or less.

This injurious effect of rubbing is of some interest because rubbing the leaf surface with virus preparations is the normal method of getting infections. It is usually assumed that the rubbing serves the purpose of wounding the epidermis and allowing virus particles to enter the cell. It seems, though, that at least two kinds of wounds are formed, and that all wounds do not favour the establishment of infection. Table 4 gives the results of experiments testing the effects of inoculating French-bean leaves once (V) or twice (VV) with RTNV and inoculating once either preceded (WV) or followed (VW) by a rub with water. Treatments (WV) and (VW), with one exception, gave fewer lesions than (V), and the same number of lesions was obtained whether the rub with water preceded or followed inoculation. This clearly suggests an effect on the host, rubbing destroying potential sites of infection, whether or not they already contain virus. In total, inoculating twice with the virus produced fewer lesions than inoculating once, though these two treatments produced very different results in different experiments. These differences 
seemed to be correlated with the condition of the plants when they were used. The leaves in Expts. C and D, when treatment (VV) produced many fewer lesions than (V), were thinner and more fragile than those used in the other experiments, when (VV) produced more lesions than (V). This suggests that the first inoculation affected the delicate leaves so that more of the possible sites of infection were made suitable for infection than in the tougher leaves, but that the second inoculation damaged many of these so much that they could no longer support virus multiplication.

The action of substances such as 'Celite' in increasing the numbers of lesions produced by a given inoculum is still imperfectly understood. It may do so, not simply because rubbing with it produces more wounds through which virus particles can enter, but because it injures cells so that their metabolism more often changes in a way that favours virus synthesis instead of preventing it. It seems unlikely that it acts by introducing virus into other cells than the epidermis and in which multiplication might occur more readily, for when we exposed leaves infected by inocula containing 'Celite' to UV, the formation of lesions was prevented as when leaves were inoculated without 'Celite'.

\section{DISCUSSION}

The results of our experiments clearly show a succession of events between the times when RTNV is inoculated to French-bean leaves and new virus becomes detectable in extracts from the leaves, but the nature of each event is less clear. Some results can be interpreted with reasonable assurance; for instance the change from a straight to a curved line in Fig. 3 most probably means that more than one potentially infective particle has appeared in most cells; also, the coincidence of the failure of UV and rubbing to affect lesion numbers can be taken as the time when virus particles have spread into the mesophyll. It is the earlier events that cannot be identified with any certainty, and the fact that they can be fitted into the sequence that occurs during infection by coliphages is suggestive, but no more than this.

As a first step in infection, coliphages are adsorbed by their hosts, and then the nucleic acid penetrates the cells. There is no direct evidence that plant viruses specifically combine with their host cells, or with any component of them; nor is there any evidence that infection necessitates the nucleic acid separating from the protein moiety. Obviously such a sequence of events is compatible with our results from floating inoculated leaves in water and treating them with ribonuclease, treatments that can prevent infection if applied shortly after leaves are inoculated but that soon become ineffective. There is, though, no need to postulate a specific attachment of the virus that prevents it from dissolving, or a fleeting period during which the nucleic acid becomes susceptible to ribonuclease. Our results are as easily explained by assuming that, during inoculation, the host cells are made permeable to large particles like viruses and ribonuclease, but that, provided the damage is not so severe that the cells die, they soon repair the wounds and regain their usual impermeability to large particles. 
The increase in resistance of the infecting virus to inactivation by UV at about $2 \mathrm{hr}$. after inoculation is again explicable by analogy with coliphages, for infection with these early leads to an increase in the nucleic acid content of the infected bacteria. There is no direct evidence that infection with RTNV increases the nucleic acid content of infected cells, but Commoner (1954) states that the insoluble nucleic acid in tobacco leaves increases before tobacco mosaic virus occurs in quantity and then decreases as the virus increases. The increase is not detectable until several days after the leaves are inoculated, but this difference in time scale from ours need not mean different phenomena. Our results are concerned only with changes in the few epidermal cells that become infected at inoculation, whereas to show differences in extracts from leaves means waiting until a considerable proportion of all the leaf cells has become infected. However, the increased resistance of RTNV to UV could have other explanations. For example, if the infecting virus does combine with, or enter, some cell components, say, mitochondria or plastids, which are rich in nucleic acid or some other substance that absorbs radiation of $2537 \mathrm{~A}$, then the virus would be protected from the radiation.

It is of some interest that new virus seems to be able to invade other leaf cells from those infected at inoculation long before it becomes detectable in extracts of macerated leaves. This could have several explanations. Palisade cells may be more easily infected than epidermal ones. Or the particles as first formed may differ from later forms, and may be able to infect cells within a leaf but lack something that makes them stable in vitro. Or it may be that there are enough specific adsorption sites nearby to fix the first particles as soon as they are formed, so that they never become freely extractable in sap. It is equally likely, however, that the interval between the time when virus becomes able to invade other cells in a leaf and the time when it becomes detectable in leaf extracts simply reflects the crudity of our inoculation methods. Spread from cell to cell may need only one virus particle, whereas, to get a single lesion, we need to apply $1 \mathrm{ml}$. of inoculum containing about $10^{5}$ particles and the lag may simply be the time taken for this concentration to be reached.

This work was done while one of us (B. D. Harrison) was a research student of the Agricultural Research Council.

\section{REFERENCES}

Bawden, F. C., Hamlyn, B. M. G. \& Watson, M. A. (1954). The distribution of viruses in different leaf tissues and its influence on virus transmission by aphids. Ann. appl. Biol. 41, 229.

Bawden, F. C. \& Kassanis, B. (1954). Some effects of thiouracil on virus-infected plants. J. gen. Microbiol. $10,160$.

Bawden, F. C. \& Kleczkowski, A. (1952). Ultra-violet injury to higher plants counteracted by visible light. Nature, Lond. 169, 90.

Bawden, F. C. \& Kueczkowskr, A. (1953). The behaviour of some plant viruses after exposure to ultraviolet radiation. J. gen. Microbiol. 8, 145.

Bawden, F. C. \& KLeCzkowski, A. (1955). Studies on the ability of light to counteract the inactivating action of ultraviolet radiation on plant viruses. J.gen. Microbiol. 13, 382. 
Benda, G. T. A. (1955). Some effects of ultra-violet radiation on leaves of French bean (Phaseolus vulgaris L.). Ann. appl. Biol. 43, 71.

Benzer, S. (1952). Resistance to ultraviolet light as an index to the reproduction of bacteriophage. J. Bact. 63, 59.

Casterman, C. \& Jeener, R. (1955). Sur le mécanisme de l'inhibition par la ribonucléase de la multiplication du virus de la mosaíque du tabac. Biochim. biophys. Acta, 16, 433 .

Commoner, B. (1954). Plant viruses and proteins. In The Dynamics of Virus and Rickettsial Infections. New York: The Blakiston Company, Inc.

Harrison, B. D. (1955). Studies on the multiplication of plant viruses in inoculated leaves. Ph.D. Thesis, University of London.

Kalmus, H. \& Kassanis, B. (1945). The use of abrasives in the transmission of plant viruses. Ann. appl. Biol. 32, 230.

Kreczkowski, J. \& Kreczkowski, A. (1954). The effect of ribonuclease on phagehost interaction. J. gen. Microbiol. 11, 451.

Kunitz, M. (1940). Crystalline ribonuclease. J. gen. Physiol. 24, 15.

LURIA, S. E. \& LATARJET, R. (1947). Ultraviolet irradiation of bacteriophage during intracellular growth. J. Bact. 53, 149.

Sieger, A. \& Wildman, S. G. (1954). Some natural relationships among strains of tobacco mosaic virus. Phytopathology, 44, 277. 